JOURNAL of

TOXICOLOGY and

ENVIRONMENTAL

HEALTH
Journal of Toxicology and Environmental Health, Part A Current Issues

\title{
Is There Sufficient Training of Health Care Staff on Noise Reduction in Neonatal Intensive Care Units? a Pilot Study From Neonoise Project
}

\section{Carlos Carvalhais, Joana Santos, Manuela Vieira da Silva \& Ana Xavier}

To cite this article: Carlos Carvalhais, Joana Santos, Manuela Vieira da Silva \& Ana Xavier (2015) Is There Sufficient Training of Health Care Staff on Noise Reduction in Neonatal Intensive Care Units? a Pilot Study From Neonoise Project, Journal of Toxicology and Environmental Health, Part A, 78:13-14, 897-903, DOI: 10.1080/15287394.2015.1051204

To link to this article: https://doi.org/10.1080/15287394.2015.1051204

Published online: 13 Jul 2015.

Submit your article to this journal $\square$

Џll Article views: 396

Q View related articles $\sqsubset$

View Crossmark data

Citing articles: 5 View citing articles $\square$ 
Journal of Toxicology and Environmental Health, Part A, 78:897-903, 2015

Copyright $\odot$ Taylor \& Francis Group, LLC

ISSN: $1528-7394$ print / 1087-2620 online

DOI: $10.1080 / 15287394.2015 .1051204$

\title{
IS THERE SUFFICIENT TRAINING OF HEALTH CARE STAFF ON NOISE REDUCTION IN NEONATAL INTENSIVE CARE UNITS? A PILOT STUDY FROM NeoNoise PROJECT
}

\author{
Carlos Carvalhais ${ }^{\circledR}$, Joana Santos ${ }^{\circledR}$, Manuela Vieira da Silva, Ana Xavier \\ Environmental Health Department and Research Centre on Health and Environment (CISA), \\ School of Allied Health Technologies of Polytechnic Institute of Porto (ESTSP.IPP), Vila Nova de \\ Gaia, Portugal
}

Evidence indicates that exposure to high levels of noise adversely affects human health, and these effects are dependent upon various factors. In hospitals, there are many sources of noise, and high levels exert an impact on patients and staff, increasing both recovery time and stress, respectively. The goal of this pilot study was to develop, implement, and evaluate the effectiveness of a training program (TP) on noise reduction in a neonatal intensive care unit (NICU) by comparing the noise levels before and after the implementation of the program. In total, 79 health professionals participated in the study. The measurements of sound pressure levels took into account the layout of the unit and locations of the main sources of noise. General results indicated that $L_{A e q}$ levels before implementation of the training program were often excessive, ranging from $48.7 \pm 2.94 \mathrm{dBA}$ to $71.7 \pm 4.74 \mathrm{dBA}$, exceeding international guidelines. Similarly, following implementation of the training program, noise levels remained unchanged (54.5 $\pm 0.49 \mathrm{dBA}$ to $63.9 \pm 4.37 \mathrm{dBA})$, despite a decrease in some locations. There was no significant difference before and after the implementation of TP. However, a significant difference was found for $L_{p, C p e a k}$, before and after training staff, suggesting greater care by health care professionals performing their tasks. Even recognizing that a TP is quite important to change behaviors, this needs to be considered in a broader context to effectively control noise in the NICU.

Evidence indicates that human exposure to high levels of noise produces physiological and psychological disorders, and that these effects are dependent upon various factors (Guthrie et al., 2014). Noise in neonatal intensive care units (NICUs) is recognized as an agent with negative implications on health and well-being of premature infants (Nicolau et al., 2005) and health professionals. Philbin and Gray (2002) documented that sound pressure levels in intensive care units ranged between 55 to 75 A-weighted decibels (dBA). These results are higher than the limit recommended by the World Health Organization (WHO), which recommends that the average background noise in hospitals should not exceed $35 \mathrm{~dB} \mathrm{~L}_{\text {Aeq }}$ for areas where patients are treated or observed. For wardrooms in hospitals the guideline values indoors are $30 \mathrm{dBA} \mathrm{L}_{\text {Aeq }}(\mathrm{A}$ weighted equivalent sound pressure level) with a corresponding $\mathrm{L}_{\text {Amax }}$ (maximum A-weighted sound pressure level) of $40 \mathrm{dBA}$ (Berglund et al., 1999). These levels are influenced by the equipment (including alarms, monitors, ventilators, infusion pumps, nebulizers) and by health professionals'/visitors' behavior (with tasks and conversation) (Short et al., 2011), as shown in Table 1 (Pugh and Griffiths, 2007).

In general, high-intensity noise levels may induce physiological instabilities in newborns, such as apnea, bradycardia, and abrupt fluctuations in heart rate, respiratory rate, blood pressure, and oxygen saturation (Philbin and Klaas, 2000; Wachman and Lahav, 2011). Complex

Address correspondence to Carlos Carvalhais, Environmental Health Department, School of Allied Health Technologies of Polytechnic Institute of Porto (ESTSP.IPP), R. Valente Perfeito, no. 322, 4400-330 Vila Nova de Gaia, Portugal. E-mail: caa@estsp.ipp.pt 
TABLE 1. Equipment and Behavioral Causes of Noise in Intensive Care Units

\begin{tabular}{ll}
\hline Source of noise & \\
\hline Items falling onto the floor & Up to $92 \mathrm{~dB}(\mathrm{~A})$ \\
Equipment movement (e.g., bed) & $90 \mathrm{~dB}(\mathrm{~A})$ \\
Connection of gas supply & $88 \mathrm{~dB}(\mathrm{~A})$ \\
Door closure & $85 \mathrm{~dB}(\mathrm{~A})$ \\
Pager & $84 \mathrm{~dB}(\mathrm{~A})$ \\
Talking & $75-85 \mathrm{~dB}(\mathrm{~A})$ \\
Ventilator alarm & $70-85 \mathrm{~dB}(\mathrm{~A})$ \\
Nebulizer & $80 \mathrm{~dB}(\mathrm{~A})$ \\
Telephone & $70-80 \mathrm{~dB}(\mathrm{~A})$ \\
Television & $79 \mathrm{~dB}(\mathrm{~A})$ \\
Oximeter & $60-80 \mathrm{~dB}(\mathrm{~A})$ \\
Monitor alarm & $79 \mathrm{~dB}(\mathrm{~A})$ \\
Ventilator & $60-78 \mathrm{~dB}(\mathrm{~A})$ \\
IV infusion alarm & $65-77 \mathrm{~dB}(\mathrm{~A})$ \\
Endotracheal aspiration unit & $50-75 \mathrm{~dB}(\mathrm{~A})$ \\
\hline
\end{tabular}

Note. Adapted from Pugh and Griffiths (2007).

exposures to multiple chemical and physical agents, such as noise, have the potential to produce several different sorts of interaction with regard to health outcomes (Fechter, 2004; Guthrie et al., 2014). Actually, noise acting in synergy with ototoxic drugs may increase the risk of sensorineural hearing loss in premature infants (American Academy of Pediatrics [AAP], 1997; Surenthiran et al., 2003). Other long-term negative effects include language difficulties and altered brain development (Brown, 2009), abnormal auditory development, and suggestion of a link between excessive noise and attention deficit hyperactivity disorder (Bremmer et al., 2003). Health professionals are concerned about this issue and identified noise as a barrier to work performance (Gurses and Carayon, 2009; Sampaio Neto et al., 2010). In fact, noise may induce extra-auditory effects in professionals, including burnout, stress, and fatigue, which results in errors (Mahmood et al., 2011).

In Portugal there has been a considerable increase in preterm births, which in 2004 increased from $6.7 \%$ to $8.8 \%$ in 2009 (Machado et al., 2011). Thus, it is essential to promote a quiet environment to reduce the impact of noise levels on health and wellbeing of premature infants and health professionals. Environmental modifications might effectively decrease noise levels (Philbin and Gray, 2002; Philbin and Klaas, 2000; Ramesh et al., 2009); however, the process of caring for hospitalized patients requires frequent and ongoing interpersonal discussions. Minimizing patient exposure to interpersonal communications between health care staff members requires a behavioral change. A well-structured training program seems to be a low-cost measure to begin noise reduction process in a hospital environment (Tsunemi et al., 2012).

The aims of this study were to (1) assess the levels of noise by measuring the equivalent sound pressure levels in zones located in NICU of a Portuguese hospital and (2) examine the influence of implementation of a training program (TP) for staff on noise reduction.

\section{MATERIALS AND METHODS}

\section{Clinical Settings}

All measurements were performed in a NICU of a hospital located in Porto, Portugal, between July 2011 (first phase-measurements taken prior to implementation of TP) and July 2012 (second phase-measurements obtained 6 months after the implementation of TP). The clinical/technical area of the unit consists of two rooms (A-Intensive Care and B-Special Care), without total separation between infrastructures. Room A includes the integrated set of physical, technical, and human expertise, where newborns in critical condition with failure of vital bodily functions are assisted by advanced life support for $24 \mathrm{~h} / \mathrm{d}$. Room B also includes an integrated set of physical, technical and human expertise, intended to provide care for infants with failure of an organ or system, but not intended for neonates requiring mechanical ventilation. The existing physical infrastructure separating the compartments consists of plywood with glazed surface on top. The floor is concrete with vinyl covering, walls are made of painted plasterboard with three glass windows, and the roof is concrete. The NICU (rooms A and B) has capacity to provide care for approximately 19 patients with a total 
of 14 incubators and 5 nurseries. Both preparation of parenteral nutrition and medication are located in a common area of the two rooms, but the entrance is accessed through room A, and consequently underwent greatest amount of staff/traffic activity.

\section{Noise Measurements}

Noise level measurements were performed using a sound level meter class $1(01 \mathrm{~dB}$, model Solo-Premium). In accordance with Robertson et al. (1998), a preliminary survey was performed in order to identify noise sources. In both rooms ( $\mathrm{A}$ and $\mathrm{B}$ ) measurements were made continuously over $24 \mathrm{~h}$ in 2 areas: work stations and traffic zones (at least $1 \mathrm{~m}$ away from the walls at a height between $1 \mathrm{~m}$ and $1.65 \mathrm{~m})$. In room $\mathrm{A}$, noise was also determined inside an incubator. The measurements of peak sound pressure level $\left(L_{p}\right.$, Cpeak $)$ were made using the $C$ filter, and those of the $A$ weighted equivalent sound pressure level $\left(\mathrm{L}_{\text {Aeq }}\right)$ were obtained using the A filter, which is a frequency-weighting filter that simulates human hearing. Slow response time averaging ( $1 \mathrm{~s}$ ) was also used because it is the most appropriate response for the majority of the applications in hospitals and provides stable readings, according to Philbin and Gray (2002). To ensure accurate measurement, recording was preceded by calibration of the sound level meter (Kent et al., 2002), with an acoustic calibrator class 1 (RION, model NC-74). In analysis and interpretation of results, reference values given by WHO were used (Berglund et al., 1999).

\section{Training Program (TP)}

The TP was performed through a lecture of approximately $60 \mathrm{~min}$ and conducted by the investigators. In order to ensure that all the staff members of the NICU under study, such as physicians, nursing staff, and auxiliary staff, attended the lecture $(n=79), 14$ training sessions were given. The lecture included the results of the sound pressure levels obtained in the first phase and comparing these to the recommended values suggested by $\mathrm{WHO}$ and other regulatory agencies. The negative impact of noise on health, for both neonates and professionals, was also discussed and some actions that needed to be implemented to ensure noise reduction were undertaken. Regarding these actions, the health professionals were led to discuss and reflect on current practice, framing the problem. The health professionals were encouraged to develop an action plan to address specific noise issues, in order to be involved in the process and obtain their commitment for future implementation of noise reduction protocols. Without their commitment, the transfer of knowledge might not be effective in changing practices and behavior.

\section{Statistical Analysis}

The processing and data analysis involved descriptive statistics, with analysis of $L_{\text {Aeq }}$ and $\mathrm{L}_{\mathrm{p} \text {,Cpeak }}$ values. All tests considered a 95\% confidence interval. The normality Shapiro-Wilk test and Student's $t$-test for paired samples were applied. The software IBM SPSS (Statistical Package for the Social Sciences) 20th version and MS Excel 2013 were used for the analysis.

\section{RESULTS}

The training content and the staff perception regarding the main sources of noise in the NICU and suggestions to decrease noise in these environments are presented in Table 2. In general, the health care staff identified equipment, visitors, healthcare procedures, traffic inside the rooms, and team conversation as the main sources of noise in the NICU.

The results obtained in the two rooms of NICU before and after implementation of TP are shown in Table 3. Before implementation of $T P, L_{\text {Aeq }}(\mathrm{dBA})$ values ranged between 60.4 and $71.7 \mathrm{dBA}$ in room $\mathrm{A}$ and between 58.1 and $59.9 \mathrm{dBA}$ in room $\mathrm{B}$. Inside the incubator, $\mathrm{L}_{\text {Aeq }}$ was $48.7 \mathrm{dBA}$. After implementation of TP, $L_{\text {Aeq }}$ values in room $A$ areas ranged between 58.8 and $59.5 \mathrm{dBA}$ and in room $B$ ranged between 60.3 and $63.9 \mathrm{dBA}$. The $\mathrm{L}_{\text {Aeq }}$ values 
TABLE 2. Training Content and Feedback From Health Care Staff

\begin{tabular}{|c|c|c|}
\hline \multirow[b]{2}{*}{ Training content } & \multicolumn{2}{|l|}{ Healthcare staff feedback } \\
\hline & $\begin{array}{l}\text { Main factors that contribute } \\
\text { to the noise level on unit }\end{array}$ & Suggestions to help decrease the noise level \\
\hline 1. General concepts of noise & 1. Traffic in the room & 1. Limit number of visitors \\
\hline \multirow{3}{*}{$\begin{array}{l}\text { 2. The impact of noise exposure in a hospital } \\
\text { setting } \\
\text { 3. National legislation and international standards } \\
\text { regarding noise exposure in hospitals }\end{array}$} & 2. Visitors behaviour & 2. Keep voices down \\
\hline & 3. Equipment/alarms & 3. Improve the technology regarding the \\
\hline & $\begin{array}{l}\text { 4. Team conversation } \\
\text { 5. Some health care }\end{array}$ & $\begin{array}{l}\text { implementation of a centralized control of all the } \\
\text { alarms of NICU in workstation area }\end{array}$ \\
\hline \multirow{2}{*}{$\begin{array}{l}\text { 4. Main health effects of noise exposure of } \\
\text { neonates and health professionals }\end{array}$} & procedures & 4. More quiet at change of shift \\
\hline & & 5. Substitute for metallic materials (e.g., drug \\
\hline $\begin{array}{l}\text { 5. Presentation and discussion of results for the } \\
\text { study developed in the NICU }\end{array}$ & & $\begin{array}{l}\text { transport cars for) with others made of washable } \\
\text { plastic }\end{array}$ \\
\hline $\begin{array}{l}\text { 6. Recommendations to reduce noise in neonatal } \\
\text { units }\end{array}$ & & $\begin{array}{l}\text { 6. Perform some tasks more carefully to avoid noise } \\
\text { production }\end{array}$ \\
\hline
\end{tabular}

TABLE 3. Values of Mean $\mathrm{L}_{\text {Aeq }}(\mathrm{dBA})$ and $\mathrm{L}_{\mathrm{p}, \text { Cpeak }}(\mathrm{dBC})$, Before and After Implementation of the Training Program

\begin{tabular}{|c|c|c|c|c|c|}
\hline Room & Area & $\begin{array}{l}\mathrm{L}_{\text {Aeq }}(\mathrm{dBA}) \text {-before, } \\
\text { mean } \pm \mathrm{SD}(\min -\max )\end{array}$ & $\begin{array}{l}L_{p}, \text { Cpeak } \\
(\mathrm{dBC}) \text {-before }\end{array}$ & $\begin{array}{l}\mathrm{L}_{\text {Aeq }}(\mathrm{dBA}) \text {-after, } \\
\text { mean } \pm \mathrm{SD} \text { (min-max) }\end{array}$ & $\begin{array}{l}\mathrm{L}_{\mathrm{p}, \text { Cpeak }} \\
(\mathrm{dBC}) \text {-after }\end{array}$ \\
\hline \multirow[t]{3}{*}{ A } & $\begin{array}{l}\text { Work } \\
\text { station }\end{array}$ & $\begin{array}{c}71.7 \pm 4.74 \\
(47.8-114.6)\end{array}$ & 143.3 & $\begin{array}{r}58.8 \pm 2.72 \\
(47.6-76.4)\end{array}$ & 102.8 \\
\hline & $\begin{array}{l}\text { Traffic } \\
\text { zone }\end{array}$ & $\begin{array}{r}60.4 \pm 5.32 \\
(43.6-91.5)\end{array}$ & 115.8 & $\begin{array}{r}59.5 \pm 1.95 \\
(53.0-75.0)\end{array}$ & 101.5 \\
\hline & $\begin{array}{l}\text { Inside } \\
\text { incubator }\end{array}$ & $\begin{array}{r}48.7 \pm 2.94 \\
(42.2-68.1)\end{array}$ & 104.1 & $\begin{array}{r}54.5 \pm 0.49 \\
(53.3-65.7)\end{array}$ & 92.8 \\
\hline \multirow[t]{2}{*}{ B } & $\begin{array}{l}\text { Work } \\
\text { station }\end{array}$ & $\begin{array}{r}59.9 \pm 6.01 \\
(39.5-85.8)\end{array}$ & 106.3 & $\begin{array}{r}60.3 \pm 3.09 \\
(46.4-79.2)\end{array}$ & 99.7 \\
\hline & $\begin{array}{l}\text { Traffic } \\
\text { zone }\end{array}$ & $\begin{array}{r}58.1 \pm 3.07 \\
(43.8-82.0)\end{array}$ & 113.2 & $\begin{array}{r}63.9 \pm 4.37 \\
(47.0-82.2)\end{array}$ & 98.9 \\
\hline
\end{tabular}

Note. SD, standard deviation; $p=.917 \mathrm{~L}_{\mathrm{Aeq}}(\mathrm{dBA}) ; p=.043 \mathrm{~L}_{\mathrm{p}, \text { Cpeak }}(\mathrm{dBC})$.

inside the incubator increased to $54.5 \mathrm{dBA}$. The results demonstrated no significant differences between $L_{\text {Aeq }}$ values before and after TP implementation, although some relevant work practices concerning the impact of noise were adjusted.

The highest $L_{p, C p e a k}(d B C)$ value was found in the "work station" area of room A before TP implementation (143.3 dBC). Data showed that significant differences were found between $\mathrm{L}_{p, \text { Cpeak }}(\mathrm{dBC})$ values before and after TP. Table 4 shows the frequencies spectrum in octave bands among the areas under study. The $500 \mathrm{~Hz}$ was the frequency that had higher levels in the majority of the areas before and after the implementation of TP (room A: "traffic zone"-56.7 dBA and $56.5 \mathrm{dBA}$; room B: "work station" - 56.7 dBA and $58.7 \mathrm{dBA}$; "traffic zone" - 59.1 dBA and $53.7 \mathrm{dBA}$ ).

\section{DISCUSSION}

During TP sessions, noise was identified by professionals as a disturbing agent and exerted a negative impact (Table 2), which is in agreement with data presented by Gurses and Carayon (2009) and by Santos et al. (2014), who demonstrated that health professionals perceived "equipment" as one of the most annoying noise sources, followed by "team conversation" and "visits."

The "work station" of room A had a decrease on $L_{\text {Aeq }}$ and $L_{p}$,Cpeak values, 71.7 to $58.8 \mathrm{dBA}$ and 143.3 to $102.8 \mathrm{dBC}$, respectively (Table 3 ). It was apparent that greater care was being undertaken by professionals in carrying out their tasks regarding noise production. However, in the "traffic zone" of room $B$, the noise level increase almost $6 \mathrm{~dB}$ after the TP, probably attributed to the presence of 
visitors and other staff (from ancillary departments that did not participated in the TP) who might be the source of this rise. The $L_{\text {Aeq }}$ values obtained in the "work station" and "traffic zone" before and after the implementation of TP exceed the recommended values given by WHO for day and night periods, indicating more attention needs to be taken. Regarding the values inside the incubator, despite the elevation of $L_{\text {Aeq }}$ values after the TP (48.7 dBA to $54.4 \mathrm{dBA}$ ), the levels obtained exceeded the recommended threshold. In general, the results obtained (Table 3) may be attributed to the number of newborns that were in NICU before (14 without specific care needs) and after TP (10, of whom 2 were helped by an oximeter and ventilator, which may produce $60-78$ and 60-80 dBA, respectively [Pugh and Griffiths, 2007]). Similar data were reported by Tsunemi et al. (2012).

Data analysis revealed that low frequencies tend to have more influence on noise produced in the NICU than higher frequencies (Table 4). These results are in agreement with Gray and Philbin (2000), who stated that noise in nurseries is dominated by low frequencies, with some exceptions due to loud midfrequencies alarms. Kellam and Bhatia (2008) suggested that human speech contributes to the spike in sound energy at $500 \mathrm{~Hz}$.

Despite adherence by health care staff members to TP, there was no significant reduction of noise after TP implementation. These results suggest that it is necessary to consider several factors that may ensure the effectiveness of TP. It seems that TP impact was lost over time, but diminution of $L_{p}$,Cpeak values may indicate that health professionals undertake their activities more carefully. In fact, the effectiveness of training health care professionals presents some contradictory findings in the literature (Oliveira et al., 2013). Several studies showed that the implementation of TP in this area contributed to reduction of sound average levels, although by itself this does not yield the recommended threshold levels and its impact tended to decrease over time (Philbin and Klaas, 2000). It is suggested that a TP incorporated into a more comprehensive quiet protocol, involving low-cost environmental (or other) modifications, seems to ensure decrease of noise levels (Ramesh et al., 2009), positively affecting patient well-being and improvement of satisfaction levels (Connor and Ortiz, 2009). Other studies also reported some resistance from health professionals to noise reduction programs, a factor that needs to be considered in future programs (Taylor-Ford et al., 2008). Connor and Ortiz (2009) noted in their study that staff members also believed that noise affected the physiologic, psychologic, and overall health of patients. In this study, the impact of staff education was measured by patient satisfaction scores surveys. In surveys after staff education, improvement was expressed in fewer poor ratings and an increase in good to very good ratings (Connor and Ortiz, 2009).

TABLE 4. Spectral Analysis of Noise (dB) Generated in Rooms A and B, Before and After the Implementation of the TP

\begin{tabular}{|c|c|c|c|c|c|c|c|c|c|c|}
\hline & \multirow[b]{2}{*}{ Room } & \multirow[b]{2}{*}{ Area } & \multicolumn{8}{|c|}{ Frequencies $(\mathrm{Hz})$} \\
\hline & & & 63 & 125 & 250 & 500 & 1000 & 2000 & 4000 & 8000 \\
\hline \multirow[t]{5}{*}{ Before TP } & \multirow[t]{3}{*}{ A } & Work station & 78.3 & 75.3 & 71.6 & 68.8 & 65.9 & 63.1 & 59.8 & 56.2 \\
\hline & & Traffic zone & 52.9 & 50.7 & 56.0 & 56.7 & 52.6 & 52.9 & 50.7 & 48.6 \\
\hline & & Inside incubator & 61.8 & 61.8 & 58.2 & 47.2 & 49.9 & 46.2 & 39.1 & 31.3 \\
\hline & \multirow[t]{2}{*}{ B } & Work station & 54.5 & 53.1 & 55.1 & 56.7 & 54.6 & 53.2 & 52.6 & 46.0 \\
\hline & & Traffic zone & 53.8 & 49.4 & 57.6 & 59.1 & 59.1 & 57.8 & 54.8 & 48.4 \\
\hline \multirow[t]{5}{*}{ After TP } & \multirow[t]{3}{*}{ A } & Work station & 52.7 & 55.7 & 54.8 & 55.5 & 53.3 & 51.4 & 50.6 & 45.1 \\
\hline & & Traffic zone & 48.3 & 50.8 & 53.2 & 56.5 & 53.1 & 55.8 & 51.0 & 44.9 \\
\hline & & Inside incubator & 55.1 & 53.9 & 48.0 & 46.8 & 44.5 & 37.7 & 36.9 & 27.2 \\
\hline & \multirow[t]{2}{*}{ B } & Work station & 53.9 & 49.6 & 54.2 & 58.7 & 54.6 & 52.4 & 48.3 & 40.8 \\
\hline & & Traffic zone & 51.2 & 47.3 & 51.4 & 53.7 & 50.9 & 50.5 & 52.2 & 47.6 \\
\hline
\end{tabular}




\section{CONCLUSIONS}

Noise is a common problem in NICU, and exerts significant adverse implications for health and well-being of patients and staff. Results showed that after 6 months of TP implementation, there was no significant noise reduction in the NICU and inside the incubator. However, $L_{p, C p e a k}$ data are an indication that in conjunction with other factors, a TP may be an excellent action to reduce noise levels. While recognizing the importance of TP in order to promote changes in the team's attitudes, it needs to be recognized that the effects are not long lasting. The training sessions need to be repeated more often, and physicians, nursing staff, supervisors, senior leadership, staff from related departments, and family members/visitors need to attend. Noise in all the rooms of a NICU might be reduced considerably by incorporating affordable behavioral and environmental modifications, and by renovation and/or preventive maintenance of equipment. Training the staff in order to implement quiet work behaviors is essential and needs to be seen as a first step to implement a quiet time protocol in neonatal intensive units.

\section{ORCID}

Carlos Carvalhais () http://orcid.org/00000002-4352-4555

Joana Santos (1) http://orcid.org/00000002-2777-3244

\section{FUNDING}

This work is part of the NeoNoise project, which is being conducted and supported by the Research Centre on Health and Environment (CISA) of the School of Allied Health Technologies of Polytechnic Institute of Porto (ESTSP.IPP). The authors are grateful for the assistance given by the Occupational Health Service of the Hospital Centre.

\section{REFERENCES}

American Academy of Pediatrics Committee on Environmental Health. 1997. Noise: A hazard for the fetus and newborn. Pediatrics 100: 724-727.

Berglund, B., L. Thomas, and H. S. Dietrich. 1999. Guidelines for community noise. Geneva, Switzerland. http://www. who.int/docstore/peh/noise/guidelines2.html Bremmer, P., J. F. Byers, and E. Kiehl. 2003. Noise and the premature infant: Physiological effects and practice implications. J. Obstet. Gynecol. Neonatal Nurs. 32: 447-454.

Brown, G. 2009. NICU noise and the preterm infant. J. Neonatal Nurs. 28: 165-173.

Connor, A., and E. Ortiz. 2009. Staff solutions for noise reduction in the workplace. Permanente J. 13: 23-27.

Fechter, L. D. 2004. Promotion of noiseinduced hearing loss by chemical contaminants. J. Toxicol. Environ. Health A 67: 727-740.

Gray, L., and M. K. Philbin. 2000. Measuring sound in hospital nurseries. J. Perinatol. 20: S100-S104.

Gurses, A. P., and P. Carayon. 2009. Exploring performance obstacles of intensive care nurses. Appl. Ergonom. 40: 509-518.

Guthrie, O.W., H. Xu, B.A. Wong, S.M., Mclturf, J.E. Reboulet, P.A. Ortiz and D.R. Mattie. 2014. Exposure to low levels of jetpropolusion fuels impairs brainstem encoding of stimulus intensity. J. Toxicol. Environ. Health A 77: 261-280.

Kellam, B., and J. Bhatia. 2008. Sound spectral analysis in the intensive care nursery: Measuring high-frequency sound. J. Pediatr. Nurs. 23: 317-323.

Kent, W. T., A. W. Tan, M. C. Clarke, and T. Bardell. 2002. Excessive noise levels in the neonatal ICU: Potential effects on auditory system development. J. Otolaryngol. 31: 355-360.

Machado, M. C., M. I. Alves, and M. L. Couceiro. 2011. Saúde infantil e juvenil em Portugal: Indicadores do plano Nacional de Saúde. Acta Pediátr. Port. 42: 195-204. 
Mahmood, A., H. Chaudhury, and M. Valente. 2011. Nurses' perceptions of how physical environment affects medication errors in acute care settings. Appl. Nurs. Res. 24: 229-237.

Nicolau, A. S., D. Casal, P. M. Lopes, and P. Kronenberg. 2005. O Ruído Nas Unidades Neonatais de Lisboa E Vale Do Tejo. Acta Pediátr. Port. 36: 15-21.

Oliveira, D., M. Figueiredo, and V. Batista. 2013. Ubiquidade do ruído em neonatologia: Efeitos e efectividade de medidas de controlo. Acta Pediátr. Port. 44: 234-241.

Philbin, M. K., and L. Gray. 2002. Changing levels of quiet in an intensive care nursery. J. Perinatol. 22: 455-460.

Philbin, M. K., and P. Klaas. 2000. Evaluating studies of the behavioral effects of sound on newborns. J. Perinatol. 20: S61-S67.

Pugh, R. J., and R. Griffiths. 2007. Noise in critical care. Care Crit. III 23: 105-109.

Ramesh, A., P. N. S. Rao, G. Sandeep, M. Nagapoornima, V. Srilakshmi, M. Dominic, and Swarnarekha. 2009. Efficacy of a low cost protocol in reducing noise levels in the neonatal intensive care unit. Indian J. Pediatr. 76: 475-478

Robertson, A., J. Kohn, P. Vos, and C. CooperPeel. 1998. Establishing a noise measurement protocol for neonatal intensive care units. J. Perinatol. 18: 126-130.

Sampaio Neto, R. A., F. O. S. Mesquita, M. D. S. Paiva Junior, F. F. Ramos, F. M. D. Andrade, and M. A. V. Correia, Jr. 2010. Ruídos Na Unidade de Terapia Intensiva: Quantificação
E Percepção Dos Profissionais de Saúde. Rev. Brasil Terap. Intensiv. 22: 369-374.

Santos, J., C. Carvalhais, M. Nóia, J. S. Baptista, and M. V. da Silva. 2014. NeoNoise Project: Preliminary results of sound pressure levels in a neonatal intensive care unit. In SHO2014: Proceedings book of the International Symposium on Occupational Safety and Hygiene, ed. P. Arezes, J. S. Baptista, M. P. Barroso, P. Carneiro, P. Cordeiro, N. Costa, R. Melo, A. S. Miguel, and G. Perestrelo, 376-378. Guimarães, Portugal: Portuguese Society of Occupational Safety \& Hygiene.

Short, A. E., K. T. Short, A. Holdgate, N. Ahern, and J. Morris. 2011. Noise levels in an Australian emergency department. Aust. Emerg. Nurs. J. 14: 26-31.

Surenthiran, S. S., K. Wilbraham, J. May, T. Chant, A. J. B. Emmerson, and V. E. Newton. 2003. Noise levels within the ear and postnasal space in neonates in intensive care. Arch. Dis. Child. Fetal Neonatal Ed. 88: F315-F318.

Taylor-Ford, R., A. Catlin, M. LaPlante, and C. Weinke. 2008. Effect of a noise reduction program on a medical-surgical unit. Clin. Nurs. Res. 17: 74-88.

Tsunemi, M. H., T. Y. Kakehashi, and E. M. Pinheiro. 2012. Noise at the neonatal intensive care unit after the implementation of an educational program. Texto ContextoEnfermagem 21: 775-782.

Wachman, E. M., and A. Lahav. 2011. The effects of noise on preterm infants in the NICU. Arch. Dis. Child. Fetal Neonatal Ed. 96: F305-F309. 